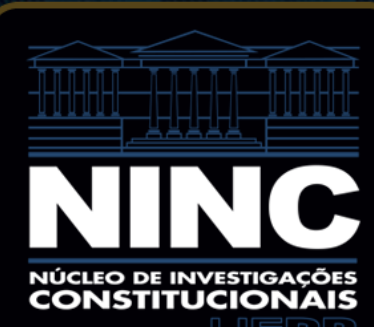




\section{Direitos humanos e fundamentais entre o Direito Constitucional Comparado e o Direito Internacional}

\section{Human and fundamental rights between the Comparative Constitutional Law and International Law}

O Direito Constitucional cultivado na segunda metade do século XX, mercê dos processos de derrubada de regimes totalitários e redemocratização dos países até então dominados por governos autoritários, encontrou nos direitos humanos e fundamentais um terreno fértil de desenvolvimento. De um lado, a promulgação de Constituições generosas na enunciação de direitos estimulou as pesquisas no campo dos direitos fundamentais. De outro, a expansão dos sistemas global e regionais de proteção dos direitos humanos atraiu os olhares dos pesquisadores para a necessidade de aproximação, interconexão e diálogo entre os ordenamentos jurídicos nacionais e a tutela internacional dos direitos humanos.

Os estudos escolhidos para a presente edição são marcados por essa tônica, apresentando os resultados de investigações que giram em torno da temática dos direitos humanos e fundamentais, ora sob o viés do Direito Comparado, ora sob a perspectiva da inter-relação entre o Direito Constitucional e o Direito Internacional dos Direitos Humanos.

Como citar este editorial | How to cite this editorial: HACHEM, Daniel Wunder. Editorial: Direitos humanos e fundamentais entre o Direito Constitucional Comparado e o Direito Internacional. Revista de Investigações Constitucionais, Curitiba, vol. 1, n. 2, p. 4-6, maio/ago. 2014. DOI: http://dx.doi.org/10.5380/rinc.v1i2.44819. 
Entre eles, encontram-se artigos em 4 idiomas (inglês, espanhol, italiano e português), de autoria de professores filiados a 6 universidades de 4 países diversos (Itália, Argentina, Uruguai e diferentes Estados da federação brasileira - Rio Grande do Sul e Rio de Janeiro). Dos artigos publicados nesta edição, 100\% são de Professores Doutores, $83 \%$ redigidos em língua estrangeira, $71 \%$ de autores estrangeiros e $100 \%$ de autores exógenos ao Estado do Paraná. São eles:

• «Talcualismo», «decolonizzazione» o «utopia arcaica» del Diritto Costituzionale?

\section{Michele Carducci}

Professore Ordinario (Titular) de Diritto Costituzionale Comparato della Università del Salento (Lecce, Italia)

- Nuevas fronteras del control de convencionalidad: el reciclaje del Derecho nacional y el control legisferante de convencionalidad

\section{Néstor Pedro Sagüés}

Profesor Emérito de Derecho Constitucional la Universidad de Buenos Aires (Buenos Aires, Argentina)

- Semantics and legal interpretation: an approach from a comparative study of the value of embryonic life under the Argentine and U.S. Constitutional case law María del Pilar Zambrano

Professor of Philosophy of Law - Universidad Austral (Buenos Aires, Argentina)

\section{Estela B. Sacristán}

Associate Professor of Administrative Law - Universidad Católica Argentina (Buenos Aires, Argentina)

- Judicial adjudication in housing rights in Brazil and Colombia: a comparative perspective

\section{Vanice Regina Lírio do Valle}

Professora Permanente do Programa de Pós-Graduação em Direito da Universidade Estácio de Sá - UNESA (Rio de Janeiro-RJ)

- La jurisprudencia de la Corte Interamericana de Derechos Humanos en la perspectiva del Derecho Administrativo. Especial referencia al caso Gelman vs. Uruguay

\section{Augusto Durán Martínez}

Profesor Catedrático de Derecho Administrativo en la Facultad de Derecho de la Universidad de la República y en la Facultad de Derecho de la Universidad Católica del Uruguay (Montevideo, Uruguay) 
- Aspectos constitutivos da teoria da argumentação jurídica: a contribuiç̧ão de Robert Alexy

\section{Rogério Gesta Leal}

Professor Titular da Universidade de Santa Cruz do Sul - UNISC (Santa Cruz do Sul-RS) e da UNOESC.

Espera-se, com a divulgação dos trabalhos acima relacionados, instigar os leitores ao estudo e à pesquisa no âmbito dos direitos humanos e dos direitos fundamentais, com o propósito de encontrar soluções jurídicas para os principais desafios encontrados atualmente nessa seara.

Curitiba, maio de 2014.

\section{Prof. Dr. Daniel Wunder Hachem}

Coordenador Editorial da Revista de Investigações Constitucionais 